\title{
Efficacy of low dose magnesium sulphate regime and Pritchard's regime in controlling of eclamptic convulsion and prevention of recurrence
}

\author{
Suryaprakash Jagdevappa Karande ${ }^{1 *}$, Archana S. Shah ${ }^{2}$
}

\author{
${ }^{1}$ Department of Obstetrics and Gynecology, Ashwini Rural Medical College, Hospital and Research Centre, Kumbhari, \\ Solapur, Maharashtra, India \\ ${ }^{2}$ Department of Obstetrics and Gynecology, Deep Super Speciality Hospital, Solapur, Maharashtra, India
}

Received: 26 November 2018

Accepted: 29 December 2018

\author{
*Correspondence: \\ Dr. Suryaprakash Jagdevappa Karande, \\ E-mail: sjkarande2000@yahoo.co.in
}

Copyright: () the author(s), publisher and licensee Medip Academy. This is an open-access article distributed under the terms of the Creative Commons Attribution Non-Commercial License, which permits unrestricted non-commercial use, distribution, and reproduction in any medium, provided the original work is properly cited.

\begin{abstract}
Background: Eclampsia is defined as the onset of convulsions or coma during pregnancy or in post-partum period in a patient who has signs and symptoms of pre-eclampsia. It is life threatening emergency that continues to be a major cause of serious maternal morbidity and mortality also along with high perinatal mortality and morbidity. The present study undertaken to determine the efficacy of low dose magnesium sulphate regime and Pritchard's regime in controlling eclamptic convulsion and prevention of recurrence of convulsion.

Methods: Out of total 60 patients enrolled in the study; 30 were given low dose magnesium sulphate regime and remaining 30 with Pritchard's regime. Selection of patients was done with simple random sampling. Relevant history was obtained from the patient, if conscious, or from the relatives. Through clinical examination was done and blood samples were collected for investigations after securing IV line.

Results: There was insignificant difference regarding type of eclampsia in both groups. Recurrence of convulsion in Pritchard's regime group was $6.67 \%$ and in Low dose regime group found to be $10 \%$ but this was statistically insignificant. Total dose of magnesium sulphate required in Low dose regime group was less than that required for Pritchard's regime.

Conclusions: Low dose magnesium sulphate Regime proved equally effective as that of Pritchard's regime in control of convulsion in spite of less amount of drug and comparatively low serum magnesium levels and hence there is hardly any fear of intoxicator.
\end{abstract}

Keywords: Convulsion, Eclampsia, Low dose magnesium sulphate regime, Pritchard's regime

\section{INTRODUCTION}

Hypertensive disorders complicating pregnancy form one of the deadly triad along with haemorrhage and infection that results in a large number of maternal deaths. Eclampsia still remains the second most common cause of maternal mortality and morbidity in underprivileged population. Eclampsia is defined as the onset of convulsions or coma during pregnancy or in post-partum period in a patient who has signs and symptoms of preeclampsia.

It is life threatening emergency that continues to be a major cause of serious maternal morbidity and mortality also along with high perinatal mortality and morbidity. Magnesium sulphate is the drug of choice for the 
prevention and treatment of eclamptic convulsions. Various drugs and regimes have been advocated for management of eclampsia, but of all the anticonvulsant drugs used in last 70 years magnesium sulphate has retained its popularity. Dr. J. A. Pritchard gets the credit of popularizing magnesium sulphate therapy for eclampsia and pre-eclampsia known as 'Pritchard's Regime', which is being followed all over the world, so also in India.

Due to improved prenatal care, incidence of Eclampsia had fallen in developed country, but it is still high in developing countries. Further, in India, reports reveal that incidence ranges from 0.179 to $5 \%$ and the average being $1.5 \%{ }^{1}$

Eclampsia with an incidence of approximately 1:2000 and 1:4000 deliveries becomes a rare disease in developed countries, and it is preventable disease. ${ }^{2}$

Following the publication of the collaborative eclampsia trial (1995), there is compelling evidence that $\mathrm{MgSo}_{4}$ is superior to diazepam and phenytoin for the treatment of eclampsia.

Sibai mentioned the important characteristics of an anticonvulsant drug. ${ }^{3}$ These are: simplicity of administering and monitoring in the clinical setting and familiarity of physicians and nurses working in obstetric units with its pharmacokinetics, as well as pharmacodynamics. They are important because the margin of error for under dosing or overdosing might prove life threatening for both mother and fetus, especially in busy obstetric units or level 1 hospital.

A review of the obstetric literature in the United States during the past 60 years indicates that magnesium sulphate satisfies all the above criteria to make it an ideal anticonvulsant drug and this drug is being used at different hospitals with different dose regimes. Most of these regimes are formulated considering the western women.

Indian women on as average weigh much less than their counterparts in the western world. Keeping this in mind, a modified low dose magnesium sulphate regime is being used to suit our Indian women since many years. ${ }^{4}$ This regime found to be equally effective when compared with other regime. The concept of appropriate levels is based on the clinical experience of Pritchard. ${ }^{5}$

Dr. Pritchard's himself suggested that the dose of magnesium sulphate should be limited in women who are known to be or appear to be small (low weight). ${ }^{5}$ Administering Pritchard's regime in these women might prove hazardous with a possibility of respiratory failure. Hence, there is a need for modification of dosage of magnesium sulphate deviating from the standard regime for these women who are very small in physique and weight compared to their western counter parts.
Keeping above facts in mind, authors have undertaken the present study to compare the efficacy of serum magnesium levels in Low dose magnesium sulphate regime and Pritchard's regime might and comparison of these two regimes for other parameters like control of convulsion, perinatal outcome, maternal outcome etc.

The objective of this study is to determine the efficacy of low dose magnesium sulphate regime and Pritchard's regime in controlling eclamptic convulsion and prevention of recurrence of convulsion.

\section{METHODS}

The study was conducted at the department of Obstetrics and Gyanecology, ARMCH and RC, Kumbhari.

Out of total 60 patients enrolled in the study; 30 were given low dose magnesium sulphate regime and remaining 30 with Pritchard's regime. Selection of patients was done with simple random sampling. On admission patients are kept in eclampsia room where doctors and nursing staff are available round the clock.

Relevant history was obtained from the patient, if conscious, or from the relatives. Through clinical examination was done and blood samples were collected for investigations after securing IV line.

In unconscious patients suctioning of mouth, nares and throat were done periodically. All the patients were catheterized to record urine output. According to the sampling the patients were given the drug as per Low dose or Pritchard's regime. Height and weight of the patient was recorded after delivery.

\section{Inclusion criteria}

- Women admitted to the labour room during the study period of two years.

\section{Drug regimes}

Modified low dose magnesium sulphate regime as advised by doctor was administered to the patient.

Low dose magnesium sulphate regime for eclampsia

\section{Loading dose}

$4 \mathrm{~g}$ of magnesium sulphate; diluted in 20cc of $25 \%$ dextrose, by slow intravenous intramuscular route.

\section{Maintenance dose}

$2 \mathrm{~g}$ of diluted magnesium sulphate IV/IM; 3 hourly for 24 hours.

Magnesium sulphate was omitted 24 after last convulsion or delivery whichever occurred later. 
During therapy patients pulse and respiration was observed closely. Intramuscular injection was given in upper and outer quadrant of buttocks in deep plane, alternately in right and left buttock.

\section{Pritchard's regime}

Patients with eclampsia were given $4 \mathrm{~g}$ magnesium sulphate IV slowly (diluted) and $10 \mathrm{~g}$ magnesium sulphate given deep intramuscularly, $5 \mathrm{~g}$ in each buttock. Thus, $14 \mathrm{~g}$ of magnesium sulphate was given as a loading dose. This was followed by $5 \mathrm{~g}$ magnesium sulphate deep intramuscularly in alternate buttocks every 4 hourly. The regime was continued for 24 hours after delivery or 24 hours after last convulsion whichever was later.

\section{Magnesium sulphate was given only after assuring that}

- Urine output $>30 \mathrm{cc}$ since last dose.

- RR was more than $14 / \mathrm{min}$

- Presence of patellar reflex.

\section{Recurrence of convulsion in both regimes}

Additional dose of $2 \mathrm{~g} \mathrm{MgSO} 4 \mathrm{IV}$; diluted in 20cc of $25 \%$ dextrose was given slowly if convulsion recurred in between the therapy. Emergency supplies kept at the patient's bedside to control magnesium sulphate toxicity were airway, endotracheal tubes, laryngoscope, suction cannula and machine, Ambu bag, oxygen supply and $10 \%$ calcium gluconate.

\section{Obstetric management}

Patients were managed depending on the state of cervical dilatation at the time of admission. The delivery was expedited with either oxytocin drip or cerviprime instillation. Caesarean section was done only if there is any obstetrics indication or magnesium sulphate failure.

Blood sample was collected in a dry plain bulb. $15 \mathrm{~min}$, after the serum was separated the bulb was kept in the middle compartment of refrigerator. All three samples were collectively sent to private laboratory and serum magnesium level was done by dry chemistry method.

\section{Statistical analysis}

Descriptive statistics such as mean, SD and percentage were used to present the data. Statistically analysis was done applying tests of significance. (Chi-square test, $t$ test, $\mathrm{Z}$ test). A p-value less than 0.05 were considered as significant.

\section{RESULTS}

The age distribution in the patients treated with Pritchard's regime- $46.67 \%$ (i.e. 14 out of 30) cases were below 20 years of age; $53.33 \%$ (16) cases were from 21 -
30 years of age. Among the patients treated with low dose $\mathrm{MgSO} 4$ regime-50\% (i.e. 15 out of 30) patients were below 20 years of age; $50 \%$ (15) cases were from 21-30 years of age (Table 1 ). This is because most of the patients complete their obstetric career before 25 years. Also, pre-eclampsia and eclampsia known to occur in nulligravida.

Table 1: Basic characteristics.

\begin{tabular}{|l|l|l|}
\hline $\begin{array}{l}\text { Characteristics } \\
\text { Age (years) }\end{array}$ & $\begin{array}{l}\text { Low dose } \\
\text { regime }\end{array}$ & $\begin{array}{l}\text { Pritchard's } \\
\text { regime }\end{array}$ \\
\hline$\leq 20$ & $15(50 \%)$ & $14(46.67 \%)$ \\
\hline $21-30$ & $15(50 \%)$ & $16(53.33 \%)$ \\
\hline Parity & $22(73.3)$ & $25(83.3)$ \\
\hline Primigravida & $8(26.7)$ & $5(16.7)$ \\
\hline Multigravida & & \\
\hline Gestational age & $8(28.6)$ & $7(30.4)$ \\
\hline$\leq 30$ weeks & $20(71.4)$ & $16(69.6)$ \\
\hline$>30$ weeks & $28(93.3)$ & $23(76.7)$ \\
\hline Types of eclampsia & $2(6.7)$ & $7(23.3)$ \\
\hline Ante/intrapartum & $18(60)$ & $12(40)$ \\
\hline Postpartum & $13(43.3)$ & $10(33.3)$ \\
\hline Premonitory symptoms & $1(3.3)$ \\
\hline Headache & 0 & $3(10)$ \\
\hline Nausea, vomiting & $6(20)$ & 0 \\
\hline Giddiness & $1(3.3)$ & $19(63.3)$ \\
\hline Blurring of vision & $19(63.3)$ & $11(36.7)$ \\
\hline Epigastric pain & $8(26.7)$ & 0 \\
\hline Number of convulsions & $3(10)$ & \\
\hline $1-3$ & & \\
\hline $4-6$ & & \\
\hline$\geq 7$ & & \\
\hline
\end{tabular}

In the low dose MgSO4 group, 22 patients were primigravida while 25 patients in Pritchard's regime group. Eclampsia found to be more in primigravida than multigravida (Table 1).

In low dose $\mathrm{MgSO} 4$ regime group, eclampsia occurring in patients with gestational age $\leq 30$ weeks, was $28.57 \%$ and in Pritchard's regime group, it was $30.43 \%$. When convulsions occur before gestational age of 20 weeks, one should think of other causes of convulsions like space occupying lesions, epilepsy, cerebrovascular accidents, etc (Table 1). $28(93.3 \%)$ patients from low dose regime group and $23(76.6 \%)$ patients from Pritchard's regime group were cases of anti-partum eclampsia. The incidence of antepartum or intrapartum eclampsia cases is more as compared to postpartum eclampsia cases. As it was difficult to find out whether the convulsions started first, or the labour hence antepartum and intrapartum eclampsia cases were considered in one group (Table 1).

The history was elicited from the patient if she was conscious, oriented or from her relatives. Most patients had more than one premonitory symptom. 42 patients out 
of 60 patients of eclampsia were found to have premonitory symptoms preceding the convulsion. Headache was the most common complaint $(60 \%$ in low dose MgSO4 regime group and $40 \%$ in Pritchard's regime group) followed by vomiting, blurring of vision and epigastric pain (Table 1). There is statistically insignificant difference in both the groups regarding number of convulsion $(\mathrm{p}>0.05)$. Most of the patients $(63.33 \%)$ in both groups came with history of $1-3$ convulsions. 3 patients had more than 7 convulsions. These were from interior villages who had no easy access to medical services and had to use primitive modes of transport to reach the hospital (Table 1).

Table 2: Clinical findings in patients with eclampsia.

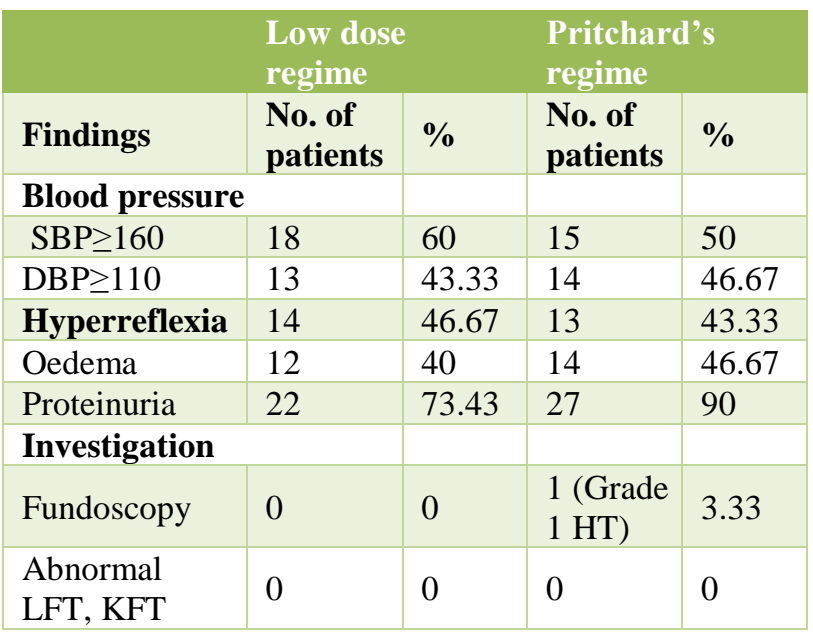

Patients with diastolic $\mathrm{BP} \geq 100 \mathrm{~mm}$ were given sublingual Nifedipine tablet $(10 \mathrm{mg})$ to avoid cerebral haemorrhage. All patients were started with Tablet Nifedepin 10mg for control of hypertension.

Majority of the patients had proteinuria in both the groups. Majority of the patients had normal fundoscopy findings except 1 patient in Pritchard's regime group whose fundoscopy revealed grade I hypertensive changes. Liver function tests and renal function tests in both groups were within normal limits (Table 2). One patient who was started with low dose magnesium sulphate regime had hypertensive encephalopathy and 1 patient form the same group had subarachnoid haemorrhage (both diagnosed by CT Scan). Both the patients were shifted to Medicine I. C. U. after delivery and they recovered completely.

Table 3: Control of convulsions after initiation of therapy.

\begin{tabular}{|l|l|l|l|l|}
\hline & \multicolumn{2}{|c|}{$\begin{array}{c}\text { Low dose } \\
\text { regime }\end{array}$} & \multicolumn{2}{c|}{$\begin{array}{c}\text { Pritchard's } \\
\text { regime }\end{array}$} \\
\hline $\begin{array}{l}\text { No. of } \\
\text { convulsion after } \\
\text { starting MgSO4 }\end{array}$ & $\begin{array}{l}\text { No. of } \\
\text { patients }\end{array}$ & $\%$ & $\begin{array}{l}\text { No. of } \\
\text { patients }\end{array}$ & $\%$ \\
\hline None & 27 & 90 & 28 & 93.33 \\
\hline One & 3 & 10 & 2 & 6.67 \\
\hline More than one & 0 & 0 & 0 & 0 \\
\hline
\end{tabular}

The efficacy of any anticonvulsant can be judged by the number of convulsions that occur after initiation of therapy. 3 patients from low dose regime group and 2 patients from Pritchard's regime group had one convulsion. None of the patients in both groups had more than 1 convulsion. These patients received additional 2 gm. Dose apart from their treatment schedule for control of convulsions (Table 3). Recurrence in Pritchard's regime group to be $6.67 \%$ and that in low dose regime group found to be $10 \%$ which is statistically insignificant $(\mathrm{p}>0.05)$.

\section{Sample collection}

$\mathrm{I}: 1 / 2$ hour after loading dose

II: $1 / 2$ hour after 1 st maintenance dose

III: $1 / 2$ hour before 2 nd maintenance dose.

All the serum magnesium levels obtained by dry chemistry method.

Table 4: Serum magnesium levels in eclampsia patients.

\begin{tabular}{|l|l|l|l|l|l|l|}
\hline $\begin{array}{l}\text { Serum Mg levels } \\
(\mathbf{m g} / \mathbf{d l})\end{array}$ & Sample I & Sample II & Sample III & Sample I & Sample II & Sample III \\
\hline $0-4$ & 6 & 9 & 19 & 1 & 1 & 3 \\
\hline $4.01-7.99$ & 20 & 18 & 11 & 22 & 20 & 25 \\
\hline 8 and above & 4 & 3 & 0 & 7 & 9 & 2 \\
\hline $\begin{array}{l}\text { Average serum } \\
\text { magnesium level }\end{array}$ & $5.45 \pm 1.97 *$ & $4.99 \pm 1.73 \#$ & $4.23 \pm 1.34 \$$ & $6.97 \pm 1.90 *$ & $7.00 \pm 1.93 \#$ & $5.73 \pm 1.6 \$$ \\
\hline
\end{tabular}

*,\#, \$:p<0.001-Significant difference of samples between low dose regime and Pritchard's regime

Only one patient who was receiving Pritchard's regime had absent knee jerk and her serum magnesium levels were I-10.2mg/dl, II-9.9mg/dl, III-10.08mg/dl. Rest of the deep tendon reflexes like triceps, biceps, supinator were present. Her urine output was $>30 \mathrm{ml} / \mathrm{hr}$. So, she was continued with the therapy. Patients with serum 
magnesium levels above $8 \mathrm{mg} / \mathrm{dl}$ did not show magnesium toxicity. None of the patients required use of calcium gluconate for magnesium sulphate intoxication.

In both the groups average serum magnesium levels were in the therapeutic range i.e. between $4.8-8.4 \mathrm{mg} / \mathrm{dl}$ as described by Pritchard. Range of serum magnesium level in Pritchard's regime was $4.67-8.45 \mathrm{mg} / \mathrm{dl}(6.56 \pm 1.89)$ and in low dose regime group was $3.14-6.74 \mathrm{mg} / \mathrm{dl}$ (4.89 \pm 1.75$)$. Further, it was found that there is a significant difference in serum magnesium level range of both groups $(\mathrm{p}<0.001)$ (Table 4$)$.

Table 5: Total dose of $\mathrm{MgSO}_{4}$ received.

\begin{tabular}{|l|l|l|l|l|}
\hline & \multicolumn{2}{c}{$\begin{array}{c}\text { Low dose } \\
\text { regime }\end{array}$} & \multicolumn{2}{c|}{$\begin{array}{c}\text { Pritchard's } \\
\text { regime }\end{array}$} \\
\hline Total dose in g & $\begin{array}{l}\text { No. of } \\
\text { patients }\end{array}$ & $\%$ & $\begin{array}{l}\text { No. of } \\
\text { patients }\end{array}$ & $\%$ \\
\hline 20 and below & 18 & 60 & - & - \\
\hline $20-30$ & 10 & 33.33 & - & - \\
\hline $31-40$ & 2 & 6.67 & - & - \\
\hline $41-50$ & - & - & 16 & 53.33 \\
\hline $51-60$ & - & - & 9 & 30 \\
\hline 61 and above & - & - & 5 & 16.67 \\
\hline
\end{tabular}

Total dose of magnesium sulphate required in low dose regime is less than that required for Pritchard's regime. Maximum dose of $\mathrm{MgSO}_{4}$ given for Pritchard's regime was $114 \mathrm{~g}$ over a period of 87 hours (Table 5).

Table 6: Mode of delivery.

\begin{tabular}{|l|l|l|l|l|}
\hline & \multicolumn{2}{|c|}{$\begin{array}{c}\text { Low dose } \\
\text { regime }\end{array}$} & \multicolumn{2}{c|}{$\begin{array}{c}\text { Pritchard's } \\
\text { regime }\end{array}$} \\
\hline $\begin{array}{l}\text { Mode of } \\
\text { delivery }\end{array}$ & $\begin{array}{l}\text { No. of } \\
\text { patients }\end{array}$ & $\%$ & $\begin{array}{l}\text { No. of } \\
\text { patients }\end{array}$ & $\%$ \\
\hline $\begin{array}{l}\text { Vaginal- } \\
\text { instrumental }\end{array}$ & 0 & 0 & 3 & 10 \\
\hline $\begin{array}{l}\text { Vaginal-non } \\
\text { instrumental }\end{array}$ & 28 & 93.33 & 22 & 73.33 \\
\hline $\begin{array}{l}\text { Caesarean } \\
\text { section }\end{array}$ & 2 & 6.67 & 5 & 16.67 \\
\hline
\end{tabular}

Out of 30 patients, 2 patients underwent caesarean section in low dose regime group and 5 patients underwent caesarean section in Pritchard's regime group. All the caesarean sections were done for obstetric indications (Table 6).

Table 7: Neonatal outcome.

\begin{tabular}{|l|l|l|}
\hline Neonatal outcome & $\begin{array}{l}\text { Low dose } \\
\text { regime }\end{array}$ & $\begin{array}{l}\text { Pritchard's } \\
\text { regime }\end{array}$ \\
\hline Live birth & 21 & 25 \\
\hline Still birth & 9 & 5 \\
\hline Neonatal death & 0 & 2 \\
\hline $\begin{array}{l}\text { Corrected perinatal } \\
\text { mortality rate }\end{array}$ & $28.57 \%$ & $28 \%$ \\
\hline
\end{tabular}

To determine the perinatal mortality in eclampsia still births below $1 \mathrm{~kg}$ were not included as these patients were induced from management point of view. So, the corrected perinatal mortality in eclampsia patients in low dose regime group is $28.57 \%$ and Pritchard's regime group is $28 \%$ (statistically insignificant). 3 fresh still births weighing $<1 \mathrm{~kg}$. So, they are excluded while calculating corrected perinatal mortality. Out of 9 still births in low dose regime group, 3 babies were below 1 $\mathrm{kg}$. weight, 3 babies were preterm, 3 babies were term babies. Only 1 patient had IUD before admission. Out of 5 still births in Pritchard's regime group, 3 babies were preterm, and 2 babies were term and in all of these patients FHS were present at the time of admission (Table 7).

No maternal death occurred in the present study.

\section{DISCUSSION}

\section{Age distribution}

No much difference regarding age distribution found in both the group. All the patients were below 30 and majority of them were younger than 25 years $(93.33 \%$ in both groups). In Sibai's study $87 \%$ patients were younger than 25 years, whereas in study done by Ranjana, majority of patients belongs to age group 20-25 years. . $^{3,6}$ There is insignificant difference regarding parity, residence and gestational age of the patients, in both groups.

\section{Types of eclampsia}

In majority of cases of type of Eclampsia as antepartum eclampsia observed by Pritchard's study (91.21\%), Sibai's (71\%), Mohanapu S (35\% low dose magnesium sulphate therapy and $60 \%$ with Pritchard's regime) and Ranjana (55\%).,

In present study $93.33 \%$ cases were of antepartum eclampsia in low dose regime group at $76.67 \%$ cases antepartum eclampsia were in Pritchard's group. In the present study there is no significant difference in both groups regarding type of Eclampsia $(\mathrm{p}>0.05)$.

\section{Number of convulsions preceding initiation of magnesium sulphate therapy}

According to study by Sardesai et al, $89.83 \%$ cases had 16 convulsions prior to magnesium sulphate therapy. ${ }^{4} 88 \%$ cases had 1-6 convulsions in Dhaka regime and $84 \%$ in Pritchard;s regime, the study by Charaku S. ${ }^{8}$

In present study, 90\% cases in low dose regime group $100 \%$ cases in Pritchard's regime group had 1-6 convulsions prior to magnesium sulphate therapy. There is insignificant difference in both groups in present study regarding number of convulsions $(\mathrm{p}>0.05)$. 


\section{Control of convulsion after initiation of therapy}

Pritchard's study utilized the Parkaland Memorial Hospital eclampsia regime on 245 eclampsia cases, of these amongst series of 83 eclampsia cases, there were recurrent seizures in $10(12.1 \%)$ cases. ${ }^{5}$ Sibai published a study on 254 eclampsia cases in 1990. 36 out of 254 cases $(14.2 \%)$ had one or more convulsion. ${ }^{3}$

For recurrent convulsions Pritchard used additional dose of $\mathrm{MgSO}_{4}$ in 9 cases and in one case Sodium amobarbital was used. Sibai used short acting barbiturate in 3 cases, i.v. pentothal drip for one patient and muscular paralysis with endotracheal intubation was done in one case. Rest of 30 patients remained seizure free with additional dose of Magnesium Sulphate. ${ }^{3}$

Sardesai et al did a study of 570 case of eclampsia. ${ }^{4}$ All patients were given low dose regime as described earlier. The recurrence rate found to be $7.89 \%$. All patients received an additional dose of $2 \mathrm{~g}$. Magnesium Sulphate except one patient who required addition of thiopental sodium and immediate termination of pregnancy. Begum $\mathrm{R}$ (from Dhaka) did a study of 65 patients of eclampsia using low dose dhaka regime (loading dose-10g. ${ }^{9}$ Magnesium sulphate followed by $2.5 \mathrm{~g}$ every 4 hourly i.m.). She found recurrence of convulsion in only one $(1.53 \%)$ patient.

In the present study, recurrence of convulsion found to be in 3 patients $(10 \%)$ in low dose regime group and 2 patients (6.67) in Pritchard's regime group. All the convulsion cases were controlled with additional $2 \mathrm{~g}$ magnesium sulphate. Failure rate of magnesium sulphate regime reported by Pritchard et al and Sibai was 1-2\% while Sardesai et al reported a failure rate of low dose magnesium sulphate to be $0.18 \% .^{3-5}$ It is unknown if abolishment of seizure activity is a function of magnesium sulphate therapy or simply the self-limited nature of the seizure activity itself. ${ }^{10}$

\section{Serum magnesium levels}

Dr. Pritchard described the therapeutic serum magnesium level to be $4.8-8.4 \mathrm{mg} / \mathrm{dl}$. Begum $\mathrm{R}$ found out serum magnesium levels in 65 cases of eclampsia giving them low dose (Dhaka) regime. ${ }^{9}$ The range of the level of serum magnesium was $1.74-6 \mathrm{mg} / \mathrm{dl}$.

In present study the range of serum magnesium level is 4.67-8.45mg/dl in Pritchard's regime group and 3.14$6.75 \mathrm{mg} / \mathrm{dl}$ in low dose regime group.In the present study, there is statistically significant difference between these two levels of serum magnesium level in both groups $(\mathrm{p}<0.001)$.

\section{Total dose of $\mathrm{MgSO}_{4}$ received}

In the study conducted by Ranjana, majority of received a total dose of 21-25g (75\%) followed by $16-20 \mathrm{~g}(15 \%)$ and $10 \%$ of cases received a total dose of less than $15 \mathrm{~g}$ in Dhaka regime.

In present study all the patients of low dose regime group required the total dose of magnesium sulphate less than $40 \mathrm{~g}$. $60 \%$ required a dose below $20 \mathrm{~g}$. All the patients of Pritchard's regime group required the total dose of more than $40 \mathrm{~g}$. $53.33 \%$ required total dose between $41-50 \mathrm{~g}$. Maximum dose of magnesium sulphate required for Pritchard' regime was $114 \mathrm{~g}$ over a period of 87 hours.

\section{Perinatal outcome}

Perinatal mortality depends on many factors gestational age, prompt arrival at hospital, availability of neonatal intensive care unit with al equipment's required for vigilant monitoring, experience of attending personnel and technology. The overall perinatal mortality in Pritchard's and Sibai's studies was $15.70 \%$ and $11.80 \%$ respectively. ${ }^{3}$ Desai reported study of eclampsia patients on Pritchard's regime of magnesium sulphate the perinatal mortality rate was $33.83 \%$. Perinatal mortality rate in the study by Sardesai et al was found $33.98 \% .^{4}$ Perinatal mortality rate in the study by Laxmi $\mathrm{M}$ was reported $20 \%$ in low dose magnesium sulphate regime and $37.14 \%$ with Pritchard's regime. ${ }^{11}$ The perinatal mortality rate in the present study is $28.57 \%$ and $28 \%$ in Low dose Regime and Pritchard's regime respectively.

\section{Maternal mortality}

The equivalent maternal outcome in the patients of Pritchard's and Sibai's series is attributed to the use of standardized protocol and availability of appropriate intensive care facilities. ${ }^{3}$ Maternal mortality $2.5 \%$ in Dhaka regime and 5\% in Pritchard regime was reported in the study done by Ranjana. ${ }^{6}$

There is an important role of early and proper referral of eclamptic patients to centers with appropriate facilities and use of standardized treatment protocol for control of convulsion, in declining the maternal mortality. In the present study, no maternal mortality was occurred.

\section{CONCLUSION}

To bring down the maternal and perinatal mortality and morbidity in cases of eclampsia control of convulsion should be the first step to be done in association with other steps of management. Magnesium sulphate has remained the drug of choice and is being used with variety of protocols.

Low dose magnesium sulphate regime proved equally effective as that of Pritchard's regime in control of convulsion in spite of less amount of drug and comparatively low serum magnesium levels and hence there is hardly any fear of intoxicator. Also, this low dose regime requires simple clinical monitoring and can be administered in any type of hospital set up, where 
facilities for intensive monitoring or serum magnesium levels estimation are not available.

The key issue is maternal transport in rural areas after they start eclamptic convulsions. The general practitioner or medical officers at primary health centre can administer the loading dose of $4 \mathrm{~g}$ prior to transfer of the patients of eclampsia to a referred centre without a fear of convulsion on the way. Other principles of management like obstetric management and antihypertensive management should be used correctly and appropriately.

Funding: No funding sources

Conflict of interest: None declared

Ethical approval: The study was approved by the Institutional Ethics Committee

\section{REFERENCES}

1. Nobis PN, Hajong A. Eclampsia in India through the decades. J Obstet Gynaecol India. 2016;66(Suppl 1):172-6.

2. Bansal V, Damania KR. Hypertensive disorders in pregnancy, Fernando Arias, practical guide to high risk pregnancy and delivery. $4^{\text {th }}$ ed. Elsevier; 2015:218-229.

3. Sibai BM. Magnesium sulphate is the ideal anticonvulsant in preeclampsia-eclampsia. Am J Obstet Gynecol. 1990;162:1141-5.

4. Sardesai SP, Patil A, Maira S, Patil U. Low dose magnesium sulphate therapy for eclampsia and imminent eclampsia: Regime tailored for Indian women. Int J Gynecol Obstet. 2000;70:B45-6.

5. Pritchard JA, Cunninghan FG, Pritchard SA. The Parkland Memorial Hospital protocol for treatment of eclampsia: Evaluation of 245 cases. Am J Obstet Gynecol. 1984;148:951.

6. Ranjana, Sinha AR, Prakash C. A comparative study of low dose magnesium sulphate (Dhaka regime) and Pritchard regime for the management of impending eclampsia and eclampsia. Int J Reprod Contracept Obstet Gynecol. 2017;6:2180-5.

7. Mohanapu S, Raveendran SK, Murugaiah Y, Sen M. A comparative study of low dose magnesium sulphate therapy with standard pritchard's regime in the management of eclampsia. Int $\mathrm{J}$ Reprod Contracept Obstet Gynecol. 2016;5:2939-43.

8. Charaku S, Rajeshwari J. Comparative study of magnesium sulphate regimens -Pritchard regimen and Dhaka regimen in the management of antepartum eclampsia. Asian Pac J Health Sci. 2016;3(4):220-3.

9. Begum R. A low dose (Dhaka) Magnesium Sulphate regime for eclampsia. Acta Obstercia Gynecologica Scand. 2001;80(1):998-1002.

10. Andrea W. Prevention and treatment of eclamptic convulsions. Clinical Obstet Gynecol. 1999;42(3).

11. Laxmi M, Neha G. Can we improve maternal and foetal outcome in eclampsia by low dose magnesium sulphate? Asian J Obstet Gynecol Practice. 2011;1:17-20.

Cite this article as: Karande SJ, Shah AS. Efficacy of low dose magnesium sulphate regime and Pritchard's regime in controlling of eclamptic convulsion and prevention of recurrence. Int J Reprod Contracept Obstet Gynecol 2019;8:536-42. 